\title{
Desempenho de gotejadores operando com efluente da castanha de caju sob distintas pressões de serviço
}

\author{
Ketson Bruno da Silval, Manoel Januário da Silva Júnior ${ }^{2}$, Rafael Oliveira Batista ${ }^{3}$, \\ Delfran Batista dos Santos ${ }^{4}$, Sebastião Barbosa Filho ${ }^{5}$
}

\section{RESUMO}

Este trabalho objetivou analisar o efeito de distintas pressões de serviço no coeficiente de variação da vazão (CVQ) de sistemas de irrigação por gotejamento, operando com água residuária da castanha de caju. O experimento foi montado no esquema de parcelas subsubdivididas, tendo, nas parcelas, as pressões de serviço (70, 140, 210 e $280 \mathrm{kPa})$, nas subparcelas, os modelos de gotejadores (G1, G2 e G3) e, nas subsubparcelas, os períodos das avaliações ( $(0,20,40$, $60,80,100,120,140$ e 160 horas), no delineamento inteiramente casualizado, com três repetições. O CVQ das unidades de irrigação, bem como as características físico-químicas da água residuária, foram determinados a cada 20 h, até completar o tempo de operação de 160 h. Os resultados indicaram que a água residuária da castanha de caju representa risco de obstrução de gotejadores, em relação às características pH, cálcio, magnésio, manganês e sólidos suspensos. O entupimento parcial dos gotejadores acarretou aumento do CVQ, nas unidades de irrigação; e as unidades de irrigação que funcionaram na pressão de serviço P1 (70 kPa) apresentaram maior nível de entupimento de gotejadores, em relação às demais, em função da menor velocidade de escoamento de efluente no interior dos emissores.

Palavras-chave: reuso, irrigação localizada, entupimento.

\section{ABSTRACT}

\section{Performance of drippers operating with cashew nuts wastewater under different service pressures}

This study aimed to analyze the effect of different operating pressures in the coefficient of flow variation (CVQ) in drip irrigation systems operating with cashew nuts wastewater. The experiment design was completely randomized with three replicates in a split plot scheme, with service pressures $(70,140,210$ and $280 \mathrm{kPa})$ on plots, models emitters (G1, G2 and G3) on subplot and operation time (0, 20, 40, 60, 80, 100, 120, 140 and 160 hours) on subsubplots. The CVQ of the irrigation units and the physico-chemical characteristics of wastewaters were measured every $20 \mathrm{~h}$ until the operating time of $160 \mathrm{~h}$. The results indicated that $\mathrm{pH}$, calcium, magnesium, manganese and suspended solids of the cashew nuts wastewater represent risk of drip clogging; partial clogging of drippers caused an increase in the CVQ of the irrigation units; and irrigation units that worked at P1 (70 kPa) service pressure showed higher levels of drip clogging than the others, due to the lower flow speed of wastewater within the drippers.

Key words: reuse, trickle irrigation, clogging.

\footnotetext{
Recebido para publicação em 18/09/2012 e aprovado em 16/04/2013.

'Engenheiro-Agrônomo, Mestre. Departamento de Ciências Ambientais e Tecnológicas, Universidade Federal Rural do Semi-Árido, Avenida Francisco Mota, 572, Bairro Costa e Silva, 59625-900, Mossoró, Rio Grande do Norte, Brasil. ketsonbruno@ hotmail.com

${ }^{2}$ Engenheiro-Agrônomo, Doutor. Departamento de Ciências Ambientais e Tecnológicas, Universidade Federal Rural do Semi-Árido, Avenida Francisco Mota, 572, Bairro Costa e Silva, 59625-900, Mossoró, Rio Grande do Norte, Brasil. mjanuario@ufersa.edu.br

${ }^{3}$ Engenheiro Agrícola, Doutor. Departamento de Ciências Ambientais e Tecnológicas, Universidade Federal Rural do Semi-Árido, Avenida Francisco Mota, 572, Bairro Costa e Silva, 59625-900, Mossoró, Rio Grande do Norte, Brasil. rafaelbatista@ufersa.edu.br (autor para correspondência).

${ }^{4}$ Engenheiro-Agrônomo, Doutor. Instituto Federal de Educação, Ciência e Tecnologia Baiano, Campus Senhor do Bonfim, 48970-000, Senhor do Bonfim, Bahia, Brasil. delfran.batista@gmail.com

${ }_{5}^{5}$ Engenheiro-Agrônomo. Departamento de Ciências Ambientais e Tecnológicas, Universidade Federal Rural do Semi-Árido, Avenida Francisco Mota, 572, Bairro Costa e Silva, 59625-900, Mossoró, Rio Grande do Norte, Brasil. tiaoufersa@ hotmail.com
} 


\section{INTRODUÇÃO}

Originário da América Tropical, o cajueiro pertence à família Anacardiaceae, que inclui árvores e arbustos tropicais e subtropicais, encontrando-se disperso numa extensa faixa, compreendida entre os paralelos de $27^{\circ} \mathrm{N}$, no sudeste da Flórida, e $28^{\circ} \mathrm{S}$, na África do Sul (Rejani \& Yadukumar, 2010).

Considerada uma das mais importantes espécies cultivadas das regiões tropicais, o cajueiro ocupa, no mundo, uma área estimada em 3,39 milhões de hectares, apresentando como principais produtos de expressão econômica a amêndoa comestível e o líquido da casca da castanha (LCC). A produção mundial de castanha é estimada em 3,1 milhões de toneladas, destacando-se o Vietnã, a Índia, o Brasil e a Nigéria como principais países produtores (Oliveira, 2008).

No Brasil, a cajucultura mobiliza cerca de 280 mil pessoas e uma área cultivada de 740.000 ha, com produção de aproximadamente 250 mil toneladas de castanha e dois milhões de toneladas de pedúnculo, por ano. Distribuída em várias regiões do País, concentra-se na região Nordeste, que responde por $94 \%$ da produção nacional, e onde os maiores plantios se localizam, principalmente, nas faixas litorâneas e de transição, do Ceará, Piauí e Rio Grande do Norte. A matéria prima castanha alimenta um parque industrial formado por uma dezena de fábricas de grande porte e cerca de 80 minifábricas, responsáveis pela obtenção da amêndoa de castanha de caju - ACC, destinada, em sua maioria, à exportação, gerando em média divisas da ordem de U\$ 225 milhões anuais (Oliveira, 2008).

O cultivo de caju, bem como a extração e o processamento de castanha constituem atividades tradicionais no Nordeste, havendo registro da adoção dessa prática há mais de 50 anos. A extração e o processamento de castanha de caju constituem atividades, com grande potencial de geração de empregos, tanto na propriedade rural, quanto nas agroindústrias (Oliveira, 2008).

A escassez hídrica, em vários estados do nordeste brasileiro, potencializa o aproveitamento agrícola dos resíduos líquidos, gerados no processamento da castanha de caju, por causa da possibilidade de substituição parcial de fertilizantes químicos, diminuição do impacto ambiental, em função da redução da contaminação dos corpos hídricos receptores; um significativo aumento na produção, tanto qualitativo, quanto quantitativo; além da economia da quantidade de água direcionada para a irrigação, que pode ser utilizada para fins mais nobres, como o abastecimento público.

O processo de industrialização da castanha de caju passa por uma série de etapas, o que resulta nas águas residuárias dessas indústrias. Os efluentes líquidos do processamento da castanha de caju são gerados, principalmente, nos processos de lavagem e umidificação da castanha, lavagem dos gases e lavagem dos equipamentos utilizados no processo industrial (Chedeville et al., 2009; Lopes et al., 2011).

Os sistemas de irrigação localizada são recomendados para aplicação de águas residuárias, por causa da elevada eficiência de aplicação do efluente e do baixo risco de contaminação do produto agrícola e de operadores no campo, pela inexistência de aerossóis que, no caso da aplicação de efluentes domésticos e de criação de animais, podem conter micro-organismos patogênicos (Souza et al., 2011). No entanto, os sistemas de irrigação por gotejamento possuem emissores que apresentam alta susceptibilidade ao entupimento (Batista 2007; Duran-Ros et al., 2009; Liu \& Huang, 2009).

A formação de biofilme nos gotejadores e nas linhas laterais de sistemas de irrigação por gotejamento é o principal problema, quando da aplicação de águas residuárias (Dazhuang et al., 2009; Duran-Ros et al., 2009; Liu \& Huang, 2009).

$\mathrm{O}$ entupimento dos gotejadores acarreta redução da vazão e aumento do coeficiente de variação de vazão (CVQ) do sistema de irrigação por gotejamento, comprometendo, assim, a produção agrícola, pela desuniformidade de aplicação do efluente (Cararo et al., 2006; Souza et al., 2006).

Para a minimização do entupimento de gotejadores, o aumento na pressão de serviço torna-se uma alternativa de baixo custo, fácil operação e alta eficiência na prevenção da formação de biofilme. Mudanças na magnitude da pressão de serviço podem interferir no processo de entupimento de gotejadores, por alteração no regime de escoamento, acarretando impactos na deposição de sedimentos (Nakayama et al., 2006). Faria et al. (2002) avaliaram o efeito da elevação da pressão de serviço na rede hidráulica de um sistema de irrigação por gotejamento, quando ocorre redução na vazão por entupimento de gotejadores. Os resultados evidenciaram que a redução na vazão dos gotejadores proporcionou aumento considerável na pressão da tubulação de distribuição de água, particularmente na condição de $50 \%$ de entupimento; $80 \%$ do comprimento da malha hidráulica apresentou pressão superior à da classe de pressão da tubulação.

Diante do exposto, este trabalho objetivou analisar o efeito de distintas pressões de serviço no coeficiente de variação de vazão do efluente, em sistemas de irrigação por gotejamento, operando com água residuária gerada no processamento da castanha de caju.

\section{MATERIAL E MÉTODOS}

Este trabalho foi realizado na Unidade Experimental de Reuso de Água (UERA), instalada no Parque Zoobotânico da Universidade Federal Rural do Semi - Árido (UFERSA), em Mossoró-RN, sob coordenadas geográficas 5¹2'27" de latitude sul e $37^{\circ} 19^{\prime} 21^{\prime \prime}$ de longitude oeste. 
A água residuária resultante do processamento da castanha de caju, utilizada neste trabalho, foi proveniente de Estação de Tratamento de Efluentes (ETE), de empreendimento situado em Mossoró-RN. O efluente líquido industrial é originado no processo de umidificação da castanha in-natura, lavagem da castanha in-natura e lavagem de piso.

Para os ensaios, foi montada uma bancada experimental, em alvenaria, na UERA, com 2,0 m de largura por 8,0 m de comprimento, dotada de piso impermeabilizado, com declividade de $1 \%$ e possuindo uma canaleta com declividade de $2 \%$, para recirculação do efluente, visando à minimização das perdas por evaporação.

A jusante dessa bancada foi construído um reservatório, em alvenaria, com capacidade armazenadora para 5,0 $\mathrm{m}^{3}$. No interior da bancada experimental, foram montadas quatro unidades de irrigação por gotejamento, compostas de: um conjunto motobomba de $1,0 \mathrm{cv}$, um hidrômetro com capacidade para $1,5 \mathrm{~m}^{3} \mathrm{~h}^{-1}$, um filtro de tela com aberturas de $130 \mu \mathrm{m}$, linha de derivação, em PVC, de $32 \mathrm{~mm}$, e linhas laterais de polietileno, com diâmetro nominal de 16 $\mathrm{mm}$, dotadas de três modelos de gotejadores, conforme apresentado na Figura 1.

No início de cada linha de derivação, foram instalados registros de gaveta, para controle da pressão de serviço, nas unidades de irrigação por gotejamento (70, 140, 210 e $280 \mathrm{kPa}$ ). Na linha de derivação de cada unidade de fertirrigação, foram inseridos nove conectores. Para cada modelo de gotejador, foram instaladas três linhas laterais, com $8 \mathrm{~m}$ de comprimento. Os três tipos de gotejadores avaliados, de acordo com os fabricantes, foram selecionados com base na sua menor susceptibilidade ao entupimento e por serem muito comercializados no mercado nacional (Tabela 1$)$.
O experimento foi realizado no período de 11 de março a 20 de abril de 2012. As unidades de irrigação por gotejamento funcionaram, em média, quatro horas por dia, até completar $160 \mathrm{~h}$. Nesse período, as vazões dos gotejadores, o coeficiente de variação de vazão (CVQ) e as características físico-químicas e biológicas do efluente foram determinados.

A vazão foi medida em sete gotejadores, de todas as linhas laterais das unidades de irrigação por gotejamento, coletando-se o volume aplicado durante três minutos. A pressão de serviço foi medida, diariamente, com um manômetro de glicerina graduado de 0 a 4 atm. O desempenho das unidades de irrigação foi avaliado a cada $20 \mathrm{~h}$, durante o período de aplicação do efluente de $160 \mathrm{~h}$. Determinou-se o coeficiente de variação de vazão (CVQ), utilizando-se a equação 1 .

$C V Q=\left(\frac{\sigma_{\mathrm{Q}}}{\mathrm{Q}_{\mathrm{m}}}\right) \times 100$

em que:

CVQ - coeficiente de variação da vazão dos gotejadores, $\%$;

$\sigma_{\mathrm{Q}}$ - desvio padrão das vazões dos gotejadores, $\mathrm{L} \mathrm{h}^{-1} ; \mathrm{e}$ $\mathrm{Q}_{\mathrm{m}}$ - vazão média dos gotejadores, $\mathrm{L} \mathrm{h}^{-1}$.

As características físico-químicas e biológicas da água residuária da castanha de caju foram determinadas a cada $20 \mathrm{~h}$ de funcionamento das unidades de irrigação por gotejamento, em conformidade com as recomendações do Standard Methods (APHA, 2005). Para isso, foram medidos os valores do potencial hidrogeniônico $(\mathrm{pH})$, com peagâmetro de bancada; as concentrações de ferro total (Fe) e manganês total $(\mathrm{Mn})$, por espectrofotometria de absorção atômica; as concentrações de cálcio $\left(\mathrm{Ca}^{2+}\right)$ e

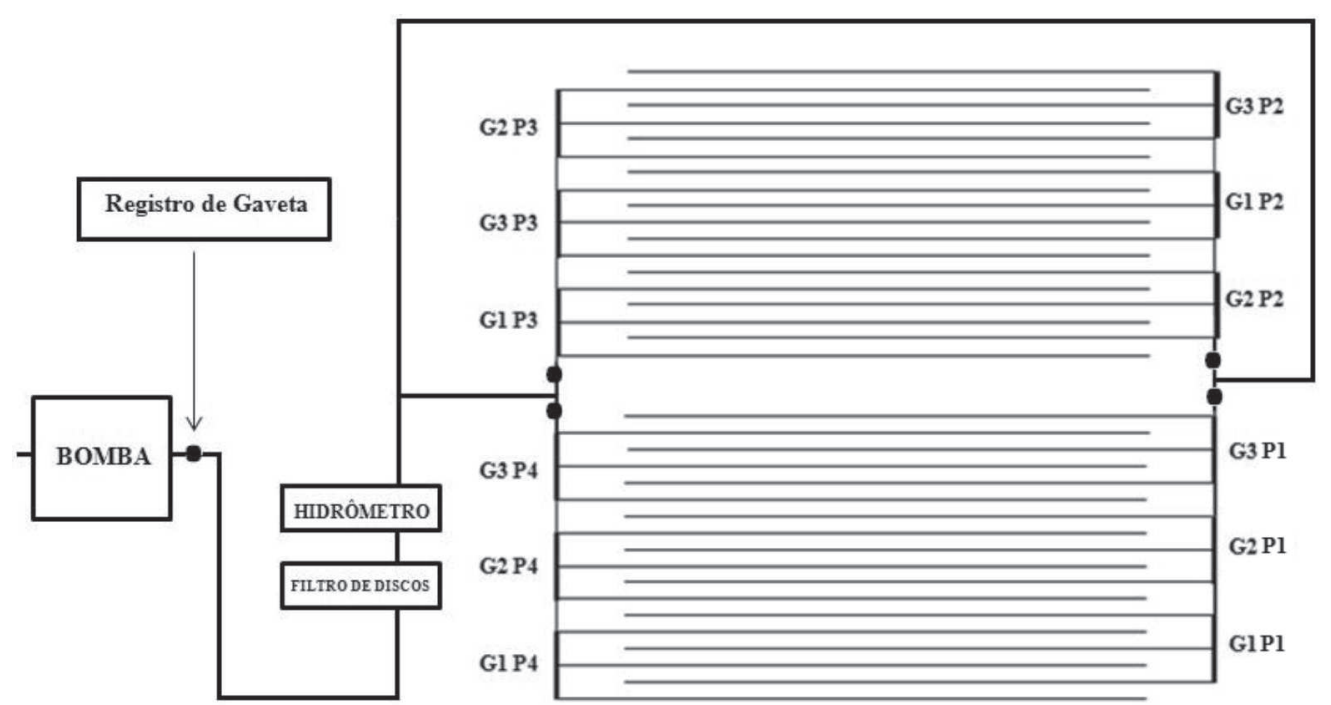

Figura 1. Esquema da bancada experimental, constituindo as quatro unidades de irrigação por gotejamento, operando nas pressões 280 (P4), $210(\mathrm{P} 3), 140(\mathrm{P} 2)$ e 70 (P1) kPa, e com os gotejadores G1, G2 e G3. 
magnésio $\left(\mathrm{Mg}^{2+}\right)$, pelo método titulométrico. As concentrações dos sólidos suspensos (SS) e dos sólidos totais (ST) foram determinadas pelo método gravimétrico, enquanto as concentrações dos sólidos dissolvidos (SD) foram obtidas pela diferença de ST e SS.

A água residuária resultante do processamento da castanha de caju, utilizada neste trabalho, foi proveniente do processo de umidificação da castanha in-natura, lavagem da castanha in-natura e lavagem de piso.

$\mathrm{O}$ experimento foi montado em esquema de parcelas subsubdivididas, tendo, nas parcelas, as pressões de serviço $(70,140,210$ e $280 \mathrm{kPa})$, nas subparcelas, os modelos de gotejadores (G1, G2 e G3) e, nas subsubparcelas, os períodos das avaliações $(0,20,40,60,80,100,120,140$ e 160 horas), no delineamento inteiramente casualizado, com três repetições, conforme a metodologia proposta por Batista (2007).

Os dados foram submetidos à análise de variância (ANOVA), empregando-se o teste $\mathrm{F}$ a $5 \%$ de probabilidade. As médias foram comparadas, utilizando-se o teste Tukey, a 5\% de probabilidade.

\section{RESULTADOS E DISCUSSÃO}

Na Tabela 2, estão apresentadas as médias e os desvios padrão das características físico-químicas e microbiológicas da água residuária do processamento da castanha de caju.

Verificou-se, nessa Tabela, que as características $\mathrm{pH}$, sólidos suspensos (SS) e sólidos dissolvidos (SD) representam risco severo de obstrução dos gotejadores, segundo as diretrizes apresentadas por Nakayama et al. (2006). Esses resultados corroboram, em parte, os do trabalho apresentado por Batista et al. (2011), em que o risco de obstrução de gotejadores foi classificado como severo para as características pH e SS, quando da aplicação de esgoto doméstico terciário, enquanto o risco de obstrução de gotejadores foi classificado como baixo, na carac- terística SD. Cunha et al. (2006) e Batista (2007) trabalharam com água residuária da despolpa dos frutos do cafeeiro e constataram riscos de obstrução de gotejadores, classificado como baixo, moderado e severo, para as características $\mathrm{pH}, \mathrm{SS}$ e SD. Deve-se ressaltar que o risco de obstrução dos gotejadores, relatado por Cunha et al. (2006) e Batista (2007) foi baixo, por causa de as águas residuárias da despolpa dos frutos do cafeeiro terem passado por uma unidade de pré-tratamento com filtragem.

As características manganês total (Mn) e ferro total (Fe) apresentam risco de obstrução de gotejadores classificado como moderado, conforme o estabelecido por Nakayama et al. (2006). O teor médio de Fe foi inferior ao valor de $1,7 \mathrm{mg} \mathrm{L}^{-1}$, obtido por Batista et al. (2011), em trabalho com esgoto doméstico terciário, que representou, também, risco moderado de obstrução de gotejadores. No trabalho apresentado por Batista et al. (2011), não foi constatada a presença de $\mathrm{Mn}$, no esgoto doméstico terciário, sendo o risco de obstrução de gotejadores classificado como baixo.

Segundo Capra \& Scicolone (1998), as concentrações de cálcio $\left(\mathrm{Ca}^{2+}\right)$ e magnésio $\left(\mathrm{Mg}^{2+}\right)$ apresentam risco de obstrução de gotejadores baixo e moderado, respectivamente. Esses resultados corroboram os obtidos por Liu \& Huang (2009), com esgoto doméstico tratado em sistema de lodo ativado, cujo risco de obstrução de gotejadores proporcionado por $\mathrm{Ca}^{2+} \mathrm{e} \mathrm{Mg}^{2+}$, também, foram classificados como baixo e moderado. Esses resultados assemelham-se aos obtidos por Batista et al. (2011), com esgoto doméstico terciário, em cujo trabalho tanto o $\mathrm{Ca}^{2+}$, quanto o $\mathrm{Mg}^{2+}$ apresentaram baixo risco de obstrução de gotejadores.

Na Figura 2, estão apresentados os resultados do coeficiente de variação de vazão (CVQ) dos gotejadores, nas unidades de irrigação com gotejadores G1, G2 e G3, operando com água residuária da castanha de caju, sob distintas pressões de serviço.

Tabela 1. Características dos gotejadores (G) utilizados nos ensaios: vazão nominal (Q), dispositivo de autocompensação (DA), área de filtração (A), comprimento do labirinto (L), faixa de pressão recomendada (P) e espaçamento entre emissores (EE)

\begin{tabular}{lcccccc}
\hline $\mathbf{G}$ & $\mathbf{D A}$ & $\mathbf{Q}\left(\mathbf{L} \mathbf{h}^{-\mathbf{1}}\right)$ & $\mathbf{A}\left(\mathbf{m m}^{\mathbf{2}}\right)$ & $\mathbf{L}(\mathbf{m m})$ & $\mathbf{P}(\mathbf{k P a})$ & $\mathbf{E E}(\mathbf{m})$ \\
\hline $\mathrm{G} 1$ & Não & 1,65 & 5,0 & 58 & 55 & 0,3 \\
G2 & Sim & 2,0 & 2,0 & 35 & $70-400$ & 1,0 \\
G3 & Sim & 4,0 & 2,0 & 35 & $70-400$ & 1,0 \\
\hline
\end{tabular}

Tabela 2. Valor médio e desvio padrão das características físico-químicas e microbiológicas da água residuária do processamento da castanha de caju

\begin{tabular}{|c|c|c|c|c|c|}
\hline pH & $\mathrm{Ca}^{2+}\left(\operatorname{mmol}_{\mathrm{c}} \mathrm{L}^{-1}\right) \mathrm{Mg}^{2+}\left(\operatorname{mmol}_{\mathrm{c}} \mathrm{L}^{-1}\right)$ & $\operatorname{Mn}\left(\mathrm{mg} \mathrm{L}^{-1}\right)$ & $\mathrm{Fe}\left(\mathrm{mg} \mathrm{L}^{-1}\right)$ & $\mathrm{SS}\left(\mathrm{mg} \mathrm{L^{-1 } )}\right.$ & $\mathrm{SD}\left(\mathrm{mg} \mathrm{L^{-1 }}\right)$ \\
\hline $7,61 \pm 0,55$ & $11,89 \pm 2,32$ & $0,30 \pm 0,04$ & $0,48 \pm 0,06$ & $290 \pm 101$ & $2344 \pm 110$ \\
\hline
\end{tabular}

Nota: $\mathrm{pH}=$ potencial hidrogeniônico; $\mathrm{Ca}^{2+}=$ cálcio, $\mathrm{mmol}_{\mathrm{c}} \mathrm{L}^{-1} ; \mathrm{Mg}^{2+}=$ magnésio, $\mathrm{mmol}_{\mathrm{c}} \mathrm{L}^{-1} ; \mathrm{Mn}=$ manganês total, $\mathrm{mg} \mathrm{L}^{-1} ; \mathrm{Fe}=$ ferro total, $\mathrm{mg} \mathrm{L}^{-1} ; \mathrm{SS}=$ sólidos suspensos, $\mathrm{mg} \mathrm{L}^{-1} ; \mathrm{SD}=$ sólidos dissolvidos, $\mathrm{mg} \mathrm{L}^{-1}$ 
As unidades de irrigação com gotejador G1, submetidas às pressões de serviço P1, P2, P3 e P4, nos tempos de funcionamento inicial e $160 \mathrm{~h}$, apresentaram valores de CVQ de 5 e $44 \% ; 3$ e $5 \%$; 6 e $7 \%$; e 5 e $2 \%$, respectivamente (Figura 2A). Verificou-se que, no tempo de funcionamento de 160 h, o valor de CVQ da unidade de irrigação submetida à pressão de serviço P1 foi superior a $20 \%$, recebendo, assim, a classificação inaceitável, segundo a norma ASABE EP 405 (Asabe Standards, 2003). Os demais valores de CVQ das unidades de irrigação foram inferiores a $10 \%$, sendo classificados como bons. Já as unidades de irrigação com gotejador $\mathrm{G} 2$, submetidas às pressões de serviço P1, P2, P3 e P4, nos tempos de funcionamento inicial e $160 \mathrm{~h}$, apresentaram valores de CVQ de $4 \mathrm{e}$ $7 \%$; 4 e 4\%; 5 e 8\%; e 4 e 3\%, respectivamente (Figura 2B). Verificou-se que os valores de CVQ das unidades de irrigação foram inferiores a 10\%, sendo classificados como bons, segundo a norma ASABE EP 405 (Asabe Standards, 2003). Nos tempos de funcionamento inicial e $160 \mathrm{~h}$, as unidades de irrigação com gotejador G3, submetidas às pressões de serviço P1, P2, P3 e P4, apresentaram valores de CVQ de 3 e $8 \%$; 4 e 4\%; 3 e 4\%; e 3 e 4\%, respectiva-
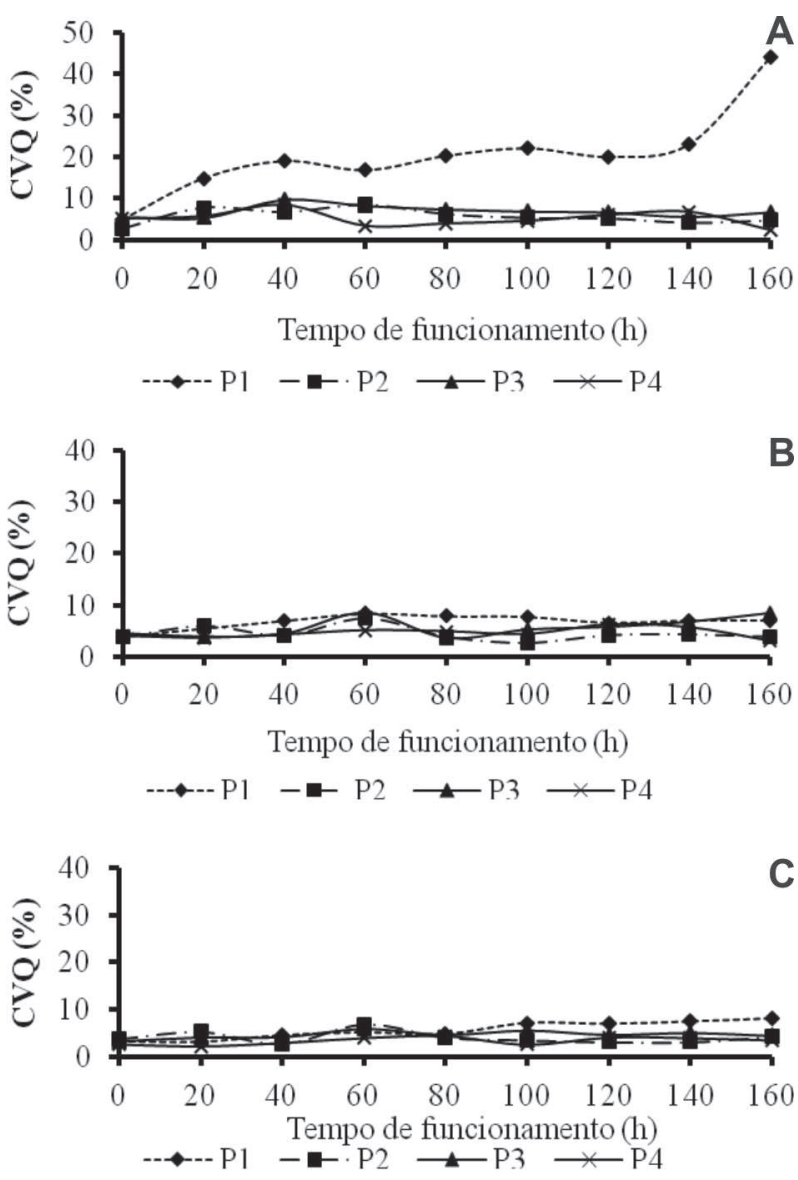

Figura 2. Valores médios do coeficiente de variação da vazão (CVQ) dos gotejadores, ao longo do período de operação, nas unidades de irrigação com gotejador G1 (A), G2 (B) e G3 (C) submetidas às pressões de serviço P1 (70 kPa), P2 (140 kPa), P3 $(210 \mathrm{kPa})$ e $\mathrm{P} 4(280 \mathrm{kPa})$. mente (Figura 2C). Verificou-se que os valores de CVQ das unidades de irrigação foram inferiores a 10\%, sendo classificados como bons, segundo a norma ASABE EP 405 (Asabe Standards, 2003). Para os gotejadores G1, G2 e G3, os valores de CVQ, obtidos com 160 h de operação, foram inferiores aos valores obtidos por Puig-Bargués et al. (2005), os quais, depois de 750h de funcionamento das unidades de aplicação, foram de 58, 35 e 5\%, para as unidades de irrigação aplicando efluente secundário, filtrado em filtro de discos de $130 \mu \mathrm{m}$, efluente secundário, filtrado em filtro de tela de $130 \mu \mathrm{m}$, e efluente terciário filtrado em filtro de tela de $130 \mu \mathrm{m}$, respectivamente.

A maior susceptibilidade ao entupimento do gotejador G1, em relação aos gotejadores G2 e G3, na pressão de serviço P1 (70 kPa), está associada ao maior comprimento de labirinto e menor vazão; nessas condições a velocidade do escoamento de efluente no interior do emissor é menor, favorecendo a formação de biofilme.

$\mathrm{Na}$ Tabela 3, encontra-se o resumo da análise de variância (ANOVA) do CVQ das unidades de irrigação com gotejadores G1, G2 e G3, sob distintas pressões de serviço, no esquema de parcelas subsubdivididas. Verificou-se que a interação P x G x T foi significativa a $1 \%$ de probabilidade, pelo teste F. Em vista do resultado da ANOVA, procedeuse ao desdobramento da interação P x G x T.

Estão apresentados na Tabela 4 os valores médios da variável CVQ das unidades de irrigação, para o fator gotejador, dentro de cada nível de tempo de funcionamento e cada nível de pressão de serviço, operando com água residuária do processamento da castanha do caju. Verificou-se, nessa Tabela, que, na pressão de serviço P1, o CVQ da unidade com o gotejador G1 diferiu do CVQ das B unidades de irrigação com gotejadores $\mathrm{G} 2$ e G3, a partir do tempo de funcionamento de $20 \mathrm{~h}$. Na pressão de serviço

Tabela 3. Resumo da análise de variância obtidas da variável CVQ, no esquema de parcelas subsubdivididas

\begin{tabular}{lcc}
\hline $\begin{array}{l}\text { Fonte de } \\
\text { variação }\end{array}$ & $\begin{array}{c}\text { Grau de } \\
\text { liberdade }\end{array}$ & $\begin{array}{c}\text { Quadrado } \\
\text { médio } \\
\text { CVQ }\end{array}$ \\
\hline Pressão de serviço (P) & 3 & $759,24^{* *}$ \\
Resíduo (a) & 6 & 6,37 \\
Tipo de gotejador (G) & 2 & $806,68^{* *}$ \\
P x G & 6 & $376,08^{* *}$ \\
Resíduo (b) & 16 & 3,06 \\
Tempo de funcionamento (T) & 8 & $52,55^{* *}$ \\
P x T & 24 & $46,15^{* *}$ \\
G x T & 16 & $21,71^{* *}$ \\
P x G x T & 48 & $26,41^{* *}$ \\
Resíduo (c) & 194 & 3,58 \\
CV (\%) parcela & & 38,90 \\
CV (\%) subparcela & & 26,98 \\
CV (\%) subsubparcela & & 29,18 \\
\hline
\end{tabular}

**F significativo a $1 \%$ de probabilidade. $\mathrm{CV}=$ coeficiente de variação. 
P2, verificou-se que o CVQ da unidade com gotejador G1 diferiu do CVQ da unidade de irrigação, com gotejador $\mathrm{G} 3$, no tempo de funcionamento de $40 \mathrm{~h}$.

Na pressão de serviço P3, foi verificado que o CVQ da unidade de irrigação com gotejador G1 diferiu do CVQ das unidades de irrigação com gotejadores G2 e G3, no tempo de funcionamento de $40 \mathrm{~h}$; o CVQ da unidade com gotejador G1 diferiu do CVQ da unidade de irrigação com gotejador G2, no tempo de funcionamento de $80 \mathrm{~h}$ e no tempo de funcionamento de 160 h, o CVQ da unidade de irrigação com gotejador G2 diferiu do CVQ das unidades de irrigação com gotejador G3. Na pressão de serviço P4, foi verificada diferença apenas no tempo de funcionamento de $40 \mathrm{~h}$, pois o CVQ da unidade de irrigação com gotejador G1 diferiu do CVQ das unidades de irrigação com gotejadores G2 e G3. Estes valores permitem afirmar que os gotejadores G2 e G3 são os mais indicados, na pressão de serviço P1(70 kPa), uma vez que ambos possuem o dispositivo de autocompensação, que minimiza o processo de obstrução. O gotejador
G1 é mais indicado para a pressão de serviço P2(140 kPa), uma vez que sua utilização torna-se mais viável, do ponto de vista econômico, com relação às pressões de serviço P3(210 kPa) e P4 (280kPa).

Constatou-se, no equipamento de aplicação, o desenvolvimento de biofilme. Em três modelos de gotejadores, os biofilmes ficaram acumulados em toda a parte interna da tubulação do sistema de irrigação. No entanto, suas ocorrências mais visíveis foram percebidas nos labirintos dos três modelos de gotejadores, conforme apresentado na Figura 3, onde estão apresentadas ilustrações dos gotejadores com a presença de biofilme.

A formação desse biofilme deveu-se, em parte, à não realização de aberturas de finais de linhas laterais para limpeza, tendo a ausência dessa prática o propósito de potencializar os efeitos do entupimento e, consequentemente, apontar o gotejador menos susceptível ao entupimento. Processo semelhante foi observado no trabalho conduzido por Batista (2007) e por Dazhuang et al. (2009).

Tabela 4. Valores médios da variável CVQ (\%) das unidades de irrigação para o fator gotejador dentro de cada nível de tempo de funcionamento e cada nível de pressão de serviço

\begin{tabular}{|c|c|c|c|c|c|}
\hline \multirow{2}{*}{$\begin{array}{l}\text { Tempo de } \\
\text { funcionamento (h) }\end{array}$} & \multirow{2}{*}{ Gotejador } & \multicolumn{4}{|c|}{ Pressão de serviço* } \\
\hline & & P1 & $\mathbf{P 2}$ & P3 & $\mathbf{P 4}$ \\
\hline \multirow{3}{*}{0} & G1 & $4,80 \mathrm{a}$ & $2,83 \mathrm{a}$ & $5,63 \mathrm{a}$ & $5,13 \mathrm{a}$ \\
\hline & $\mathrm{G} 2$ & $3,91 \mathrm{a}$ & $3,84 \mathrm{a}$ & $4,51 \mathrm{a}$ & $4,04 \mathrm{a}$ \\
\hline & G3 & $3,29 \mathrm{a}$ & $3,79 \mathrm{a}$ & $3,34 \mathrm{a}$ & $2,82 \mathrm{a}$ \\
\hline \multirow{3}{*}{20} & G1 & $14,81 \mathrm{a}$ & $7,81 \mathrm{a}$ & $5,41 \mathrm{a}$ & $5,69 \mathrm{a}$ \\
\hline & $\mathrm{G} 2$ & $5,51 \mathrm{~b}$ & $5,99 a$ & $3,87 \mathrm{a}$ & $3,68 \mathrm{a}$ \\
\hline & G3 & $3,15 b$ & $5,33 \mathrm{a}$ & $4,17 \mathrm{a}$ & $2,25 \mathrm{a}$ \\
\hline \multirow{3}{*}{40} & G1 & $19,02 \mathrm{a}$ & $6,77 \mathrm{a}$ & $9,74 \mathrm{a}$ & $8,46 a$ \\
\hline & G2 & $7,00 \mathrm{~b}$ & $4,17 \mathrm{ab}$ & $4,44 b$ & $4,30 \mathrm{~b}$ \\
\hline & G3 & $4,56 b$ & $2,77 \mathrm{~b}$ & $4,23 b$ & $2,97 b$ \\
\hline \multirow{3}{*}{60} & G1 & $16,78 \mathrm{a}$ & $8,49 a$ & $8,34 \mathrm{a}$ & $3,34 \mathrm{a}$ \\
\hline & G2 & $8,38 \mathrm{~b}$ & $7,48 \mathrm{a}$ & $8,49 a$ & $5,12 \mathrm{a}$ \\
\hline & G3 & $5,17 \mathrm{~b}$ & $6,92 \mathrm{a}$ & $5,97 \mathrm{a}$ & $4,03 \mathrm{a}$ \\
\hline \multirow{3}{*}{80} & G1 & $20,28 \mathrm{a}$ & $6,26 a$ & $7,45 \mathrm{a}$ & $3,91 \mathrm{a}$ \\
\hline & $\mathrm{G} 2$ & $7,88 \mathrm{~b}$ & $3,94 \mathrm{a}$ & $3,61 b$ & $4,92 \mathrm{a}$ \\
\hline & G3 & $4,84 b$ & $4,11 \mathrm{a}$ & $4,73 \mathrm{ab}$ & $4,46 \mathrm{a}$ \\
\hline \multirow{3}{*}{100} & G1 & $22,07 \mathrm{a}$ & $5,39 \mathrm{a}$ & $6,92 a$ & $4,53 \mathrm{a}$ \\
\hline & $\mathrm{G} 2$ & $7,78 b$ & $2,73 a$ & $5,22 \mathrm{a}$ & $4,40 \mathrm{a}$ \\
\hline & G3 & $7,15 b$ & $3,53 \mathrm{a}$ & $5,62 \mathrm{a}$ & $2,61 \mathrm{a}$ \\
\hline \multirow{3}{*}{120} & G1 & $20,03 a$ & $5,24 \mathrm{a}$ & $6,73 a$ & $6,02 \mathrm{a}$ \\
\hline & $\mathrm{G} 2$ & $6,64 b$ & $4,21 \mathrm{a}$ & $5,73 \mathrm{a}$ & $6,24 a$ \\
\hline & G3 & $6,95 b$ & $3,13 \mathrm{a}$ & $4,71 \mathrm{a}$ & $4,16 a$ \\
\hline \multirow{3}{*}{140} & G1 & $23,11 \mathrm{a}$ & $4,22 \mathrm{a}$ & $5,66 a$ & $6,75 \mathrm{a}$ \\
\hline & $\mathrm{G} 2$ & $7,07 \mathrm{~b}$ & $4,39 a$ & $6,74 a$ & $5,71 \mathrm{a}$ \\
\hline & G3 & $7,47 \mathrm{~b}$ & $3,12 \mathrm{a}$ & $5,11 \mathrm{a}$ & $4,00 \mathrm{a}$ \\
\hline \multirow{3}{*}{160} & G1 & $44,12 \mathrm{a}$ & $4,80 \mathrm{a}$ & $6,79 \mathrm{ab}$ & $2,27 \mathrm{a}$ \\
\hline & G2 & $7,11 \mathrm{~b}$ & $3,91 \mathrm{a}$ & $8,42 \mathrm{a}$ & $3,08 \mathrm{a}$ \\
\hline & G3 & $8,08 \mathrm{~b}$ & $4,34 \mathrm{a}$ & $4,49 b$ & $3,53 \mathrm{a}$ \\
\hline
\end{tabular}

* Médias seguidas de pelo menos uma mesma letra nas colunas, para cada tempo de funcionamento e pressão de serviço, não diferem entre si, a $5 \%$ de probabilidade, pelo teste de Tukey. P1 $=70 \mathrm{kPa} ; \mathrm{P} 2=140 \mathrm{kPa} ; \mathrm{P} 3=210 \mathrm{kPa}$; e P4 = $280 \mathrm{kPa}$.

Rev. Ceres, Viçosa, v. 60, n.3, p. 339-346, mai/jun, 2013 

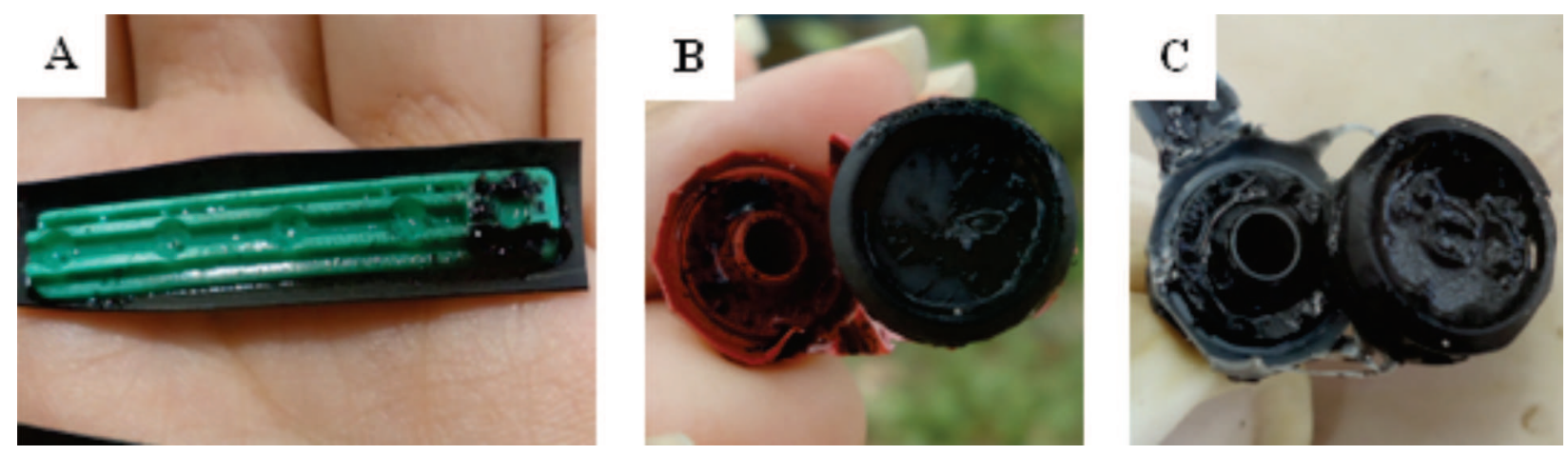

Figura 3. Gotejador G1 com a presença de biofilme (A); gotejador G2 com a presença de biofilme (B); gotejador G3 com a presença de biofilme (C).

\section{CONCLUSÕES}

A água residuária gerada no processamento da castanha de caju representa risco de obstrução de gotejadores, em relação às características $\mathrm{pH}$, cálcio, magnésio, manganês, sólidos suspensos e sólidos totais.

$\mathrm{O}$ entupimento parcial dos gotejadores acarretou aumento nos valores do coeficiente de variação de vazão das unidades de irrigação, abastecidas com água residuária do processamento da castanha de caju.

As unidades de irrigação que funcionaram na pressão de serviço P1 (70 kPa) apresentaram maior nível de entupimento de gotejadores, em relação àquelas com as pressões de serviço P2 (140 kPa), P3 (210kPa) e P4 (280 kPa).

O gotejador G1 é mais susceptível ao entupimento do que os gotejadores $\mathrm{G} 2 \mathrm{e} \mathrm{G} 3$, por causa do maior comprimento de labirinto. Esse gotejador é mais indicado sob a pressão de serviço P2 (140 kPa), quando da aplicação da água residuária gerada no processamento da castanha de caju.

Para o uso de gotejadores, é necessária a implantação de unidade de filtragem, visando à redução de sólidos suspensos, considerando-se que a água residuária gerada no processamento da castanha de caju não atendeu à legislação vigente, para lançamento de efluentes tratados em corpos hídricos, CONAMA nº 430/2011.

\section{REFERÊNCIAS}

APHA - American Public Health Association (2005) Standard methods for the examination of water and wastewater. 21. ed. Washigton, APHA/AWWA/WEF. 1268p.

American Society of Agricultural and Biological Engineers - ASABE EP 405 (2003) Design and installation of microirrigation systems. ASAE Standards, St. Joseph. p.900-905.

Batista RO, Costa FGB, Lopes HSS, Coelho DCL \& Costa Paiva MRF (2011) Efeito das características do esgoto doméstico na uniformidade de aplicação de sistemas de irrigação por gotejamento. Revista Caatinga, 24:137-144.

Batista RO (2007) Desempenhos de sistemas de irrigação por gotejamento utilizado na aplicação de água residuária de suinocultura. Tese de Doutorado. Universidade Federal de Viçosa, Viçosa. 146p.
Batista RO, Matos AT, Cunha FF \& Lo Monaco PA (2007) Formação de biofilme em gotejadores aplicando água residuária da despolpa dos frutos do cafeeiro. Acta Scientiarum. Agronomy, 29:367-371.

Capra A \& Scicolone B (1998) Water quality and distribution uniformity in drip/trickle irrigation systems. Journal of Agricultural Engineering Research, 70:355-365.

Cararo DC, Botrel TA, Hills DJ \& Leverenz HL (2006) Analysis of clogging in drip emitters during wastewater irrigation. Applied Engineering in Agriculture, 22:251-257.

Chedeville O, Debacq M \& Porte C (2009) Removal of phenolic compounds present in olive mill wastewaters by ozonization. Desalination, 249:865-869.

Cunha FF, Matos AT, Batista RO \& Lo Monaco PA (2006) Uniformidade de distribuição em sistemas de irrigação por gotejamento utilizando água residuária da despolpa dos frutos do cafeeiro. Acta Scientiarum. Agronomy, 28:143-147.

Dazhuang Y, Zhihui B, Rowan M, Likun G, Shumei R \& Peiling Y (2009) Biofilm structure and its influence on clogging in drip irrigation emitters distributing reclaimed wastewater. Journal of Environmental Sciences, 21:834-841.

Duran-Ros M, Puig-Bargue's J, Arbat G, Barraga'n J \& Ramirez de Cartagena F (2009) Effect of filter, emitter and location on clogging when using effluents. Agricultural Water Management, 96:67-79.

Faria LF, Coelho RD, Flecha PAN, Robles WGR \& Vásquez MAN (2002) Entupimento de gotejadores e seu efeito na pressão da rede hidráulica de um sistema de microirrigação. Revista Brasileira de Engenharia Agrícola e Ambiental, 6:195-198.

Liu H \& Huang G (2009) Laboratory experiment on drip emitter clogging with fresh water and treated sewage effluent. Agricultural Water Management, 96:745-756.

Lopes MSS, Oliveira PCC, Andrade MVF, Araújo RS, Marinho G \& Rodrigues K (2011) Remoção de macronutrientes de efluente da indústria de castanha de caju por uso de reator aeróbio em batelada com inoculo fúngico. Revista Engenharia Sanitária e Ambiental, 16:17-26.

Puig-Bargués J, Arbat G, Barragán J \& Ramírez de Cartagena F (2005) Hydraulic performance of drip irrigation subunits using WWTP efluents. Agricultural Water Management, 77:249-262.

Nakayama FS, Boman BJ \& Pitts D (2006) Maintenance. In: Lamm FR, Ayars JE \& Nakayama FS (Eds.) Microirrigation for crop production: Design, Operation, and Management. Amsterdam, Elsevier. p.389-430.

Oliveira VH (2008) Cajucultura. Revista Brasileira de Fruticultura, 30:01-03. 
Rejani R \& Yadukumar N (2010) Soil and water conservation techniques in cashew grown along steep hill slopes. Scientia Horticulturae, 126:371-378.

Souza JAA, Batista RO, Ramos MM \& Soares AA (2011) Contaminação microbiológica do perfil do solo com esgoto sanitário. Acta Scientiarum. Technology, 33:5-8.
Souza JAA, Cordeiro EA \& Costa EL (2006) Aplicação de hipoclorito de sódio para recuperação de gotejadores entupidos em irrigação com água ferruginosa. Revista Brasileira de Engenharia Agrícola e Ambiental, 10:5-9. 